\title{
MAPK1/ERK2 as novel target genes for pain in head and neck cancer patients
}

Cielito C. Reyes-Gibby ${ }^{1{ }^{*} \dagger}$, Jian Wang ${ }^{2 \dagger}$, Mary Rose T. Silvas ${ }^{1}$, Robert $\mathrm{Yu}^{2}$, Sai-Ching J. Yeung ${ }^{1}$ and Sanjay Shete ${ }^{2,3}$

\begin{abstract}
Background: Genetic susceptibility plays an important role in the risk of developing pain in individuals with cancer. As a complex trait, multiple genes underlie this susceptibility. We used gene network analyses to identify novel target genes associated with pain in patients newly diagnosed with squamous cell carcinoma of the head and neck (HNSCC).

Results: We first identified 36 cancer pain-related genes (i.e., focus genes) from 36 publications based on a literature search. The Ingenuity Pathway Analysis (IPA) analysis identified additional genes that are functionally related to the 36 focus genes through pathway relationships yielding a total of 82 genes. Subsequently, 800 SNPs within the 82 IPA-selected genes on the Illumina HumanOmniExpress-12v1 platform were selected from a large-scale genotyping effort. Association analyses between the 800 candidate SNPs (covering 82 genes) and pain in a patient cohort of 1368 patients with HNSCC (206 patients with severe pain vs. 1162 with non-severe pain) showed the highest significance for MAPK1/ERK2, a gene belonging to the MAP kinase family (rs8136867, $p$ value $=8.92 \times 10^{-4}$; odds ratio [OR] $=1.33$, $95 \%$ confidence interval [CI]: 1.13-1.58). Other top genes were PIK3C2G (a member of PI3K [complex], rs 10770367, $p$ value $=1.10 \times 10^{-3} ; \mathrm{OR}=1.46,95 \% \mathrm{Cl}: 1.16-1.82$ ), TCRA (the alpha chain of T-cell receptor, rs6572493, $p$ value $=2.84 \times 10^{-3}$; $\mathrm{OR}=0.70,95 \% \mathrm{Cl}: 0.55-0.88$ ), PDGFC (platelet-derived growth factor $\mathrm{C}$, rs6845322, $p$ value $=4.88 \times 10^{-3} ; \mathrm{OR}=1.32,95 \%$ Cl: 1.09-1.60), and CD247 (a member of CD3, rs2995082, $p$ value $=7.79 \times 10^{-3} ; \mathrm{OR}=0.76,95 \%$ Cl: 0.62-0.93).

Conclusions: Our findings provide novel candidate genes and biological pathways underlying pain in cancer patients. Further study of the variations of these candidate genes could inform clinical decision making when treating cancer pain.
\end{abstract}

Keywords: Cancer pain, Head and neck cancer, MAPK1/ERK2, Ingenuity pathway analysis, Gene, SNP

\section{Background}

Head and neck cancer is the sixth most common malignancy worldwide. Squamous cell cancer of the head and neck (HNSCC) is the most common head and neck cancer that includes cancers of the oral cavity (including the gums and tongue), pharynx, and larynx. Relative to other cancers, patients with head and neck cancer have a better prognosis, with overall mortality rates for head and neck cancers declining since 2001 [1]. However, as many as two thirds present with advanced stage of disease and with debilitating symptoms that impacts their quality of life [2]. Therefore, clinical management of symptoms associated with head and neck cancer and cancer treatment is an

\footnotetext{
* Correspondence: creyes@mdanderson.org

${ }^{\dagger}$ Equal contributors

'Department of Emergency Medicine, The University of Texas MD Anderson Cancer Center, Houston, TX 77030, U.S.A.

Full list of author information is available at the end of the article
}

important goal in managing patients with head and neck cancer.

Pain, which is often the first symptom of head and neck cancer, is prevalent and may be persistent, adversely affecting the quality of life of survivors [2]. Recently, we showed that pain impacts survival [2] in head and neck cancer patients. Therefore, understanding risk factors for pain has huge clinical implications. Our studies and those of others have shown that genetic factors play a key role in vulnerability to pain in cancer patients, and have identified important candidate genes such as opioid receptor genes (e.g., OPRK1 and OPRM1) [3-6], catechol-O-methyltransferase $(C O M T)$ [7, 8], and cytokine genes [9-17]. These studies mainly focused on specific biological pathways. However, as a complex human trait, it is understood that several genes underlie pain $[9,10,16,18,19]$ and a comprehensive assessment of genetic risk factors and putative biological pathways for pain is compelling. 
The purpose of this study is to identify cancer painrelated genes using a literature search following with the Ingenuity Pathway Analysis (IPA; Ingenuity ${ }^{\circ}$ Systems, www.ingenuity.com) and then to assess association between the common genetic variants within these IPAderived genes and cancer related pain in HNSCC patients. Recently, novel network-based approaches have been employed to systematically explore the molecular complexity of diseases [20-24]. Network-based approaches can provide a "big" picture that integrates epidemiological associations with the body of scientific knowledge about complex intracellular and intercellular interactions involved in diseases [23, 25]. Further, network-based approaches have the advantage of identifying disease- or phenotype-related genes and pathways, and in turn, can offer a better understanding of the underlying biological mechanisms [21]. In this study, we used IPA as a bioinformatic tool to synthesize the comprehensive pathway and network analyses of the known genes implicated in cancer pain, which we retrieved from the literature review. The network generated from the IPA core analysis suggests new candidate genes for cancer pain studies. Subsequently, we selected 800 SNPs from a large-scale genotyping effort, genotyped using Illumina HumanOmniExpress12v1 BeadChip, within the IPA-derived candidate genes and evaluated their association with pre-treatment pain in patients newly diagnosed with squamous cell carcinoma of the head and neck.

\section{Methods}

We first conducted a literature search on genetic studies of pain, as described below. Second, using genes pooled from literature as a starting point, we used IPA to generate gene networks for pain and identified additional genes that are functionally related to the genes obtained from literature search; and finally, we selected SNPs from a large-scale genotyping effort within those IPA-derived genes and assessed the association between the SNPs and pre-treatment pain in 1368 HNSCC patients.

\section{Literature search}

We used the PubMed database to perform a comprehensive literature review, limiting our search to human studies and articles published in English prior to July 2014. The primary purpose of the literature search was to identify genes associated with pain in cancer patients. The genes identified through this search will serve as "focus genes" in the IPA analyses. The search terms used were "cancer pain SNP," "cancer pain SNPs," "cancer pain gene," cancer pain genes," "cancer chronic pain SNP," "cancer chronic pain SNPs," "cancer chronic pain gene," "cancer chronic pain genes," "cancer neuropathic pain SNP," "cancer neuropathic pain SNPs," "cancer neuropathic pain gene" and "cancer neuropathic pain genes". Particularly, we used singular and plural keywords separately because we identified additional papers through such search than using only singular keywords. We screened the articles initially identified in our search on the basis of the title, abstract, and full text, and excluded duplicate articles. We then manually searched the reference lists of those articles and of related review articles to identify additional relevant articles (Table 1). From these studies, we retrieved information about genes that harbor or are close to significantly associated genetic variants (SNPs or haplotypes) and included those genes in the IPA. In particular, we included only genes that either have a known biological functional significance (e.g., mediators of the inflammatory response, multi-drug resistance, or drug metabolism) or have been replicated in an independent study.

\section{Ingenuity pathway analysis}

IPA is a system that connects a list of molecules into a set of networks using the scientific information contained in the Ingenuity Knowledge Base, which is the largest knowledge base of biological interactions and functional annotations [23, 26]. In the networks, nodes are used to represent molecules, which include genes, chemicals, protein families, complexes, microRNA species and biological processes [27]; whereas lines (edges and arrows) connecting two molecules are used to represent relationships between them.

Table 1 Numbers of articles obtained using different search terms

\begin{tabular}{lllll}
\hline Search terms & \# of articles by PubMed search & \# of articles by initial screen & \# of articles from references & \# of articles included \\
\hline Cancer pain SNPs (SNP) & 74 & 20 & 14 & 34 \\
Cancer pain genes (gene) & 1207 & 0 & 0 & 0 \\
Cancer neuropathic pain SNPS (SNP) & 4 & 0 & 0 & 0 \\
Cancer neuropathic pain genes & 78 & 2 & & 2 \\
(gene) & 12 & 0 & 0 & 0 \\
Cancer chronic pain SNPs (SNP) & 12 & 0 & 14 & 0 \\
Cancer chronic pain genes (gene) & 204 & 1579 & 22 & 36 \\
Total & 1579
\end{tabular}


In this study, we utilized the IPA core analysis function to provide interpretation for the genes identified from the literature review (denoted as focus genes in IPA) in the context of biological functions and canonical pathways, as well as to generate relevant networks identifying additional genes that interact with the focus genes. The resulting genes could be considered as candidate genes of interest for future studies of cancer pain. The network generated from IPA analysis also provides a bigger picture about the genes that are likely to be interacting and are directly or indirectly associated with the cancer pain.

The core analysis function in IPA determines biological functions, searches for signaling and metabolic canonical pathways and creates molecule networks on the basis of the focus genes [28]. The biological functions and canonical pathways are based on the literature and are independent of focus genes. The network is created using the focus genes. Each focus gene, irrespective of how many papers reported that gene, is equally weighted in the IPA core analysis. In the IPA core analyses, the key assumption in developing a network is that the biological function involves locally dense interactions [29]. The network generation algorithm involves the following steps: (1) rank the focus genes in a decreasing order based on their connectivity; (2) the most connected focus gene is used as the starting seed gene and a seed gene network is generated using a subset of remaining focus genes that are in the neighborhood of the starting seed gene. A neighborhood is defined as a gene plus the genes exactly one connection away from that gene; (3) generate the second seed gene network using the focus genes not belonging to the first seed gene network. The process continues until all focus genes are included in a seed gene network; (4) connect the seed gene networks through additional non-focus genes; (5) connect additional genes or networks from IPA's database to the existing network if the network has not reached the maximum pre-specified network size (e.g., 140 genes). Specifically, when identifying additional genes to be added, IPA gives priority to the genes that have the largest overlap with the existing network and have the least number of neighbors. This property is measured using a metric called specific connectivity, which is calculated by dividing the number of genes in the intersection of the neighborhood and the existing network by the union of the number of genes in the neighborhood and the existing network [29]. The gene with the highest specific connectivity score is included in the existing network. Importantly, with the use of this network generation algorithm, the IPA analysis can exclude a focus gene from the resulting network if such a gene is less likely to have connections (i.e., biological relationships) with the network.

The resulting functions/pathways/networks are evaluated using a right-tailed Fisher's exact test. The $p$ values obtained on the basis of this test measure the likelihood that the association between a set of focus genes and a given function/pathway/network is due to random chance [30]. The null hypothesis is that the proportion of the focus genes mapping to a function/pathway/network is similar to the proportion that are mapped in the entire reference set [28]. A score, which is assessed as $-\log _{10}(p$ value), is used to rank the resulting functions/pathways/networks. We used a significance level of $<10^{-5}$ in our study (score $>5$ ) when selecting networks as used in previous studies [23].

In our IPA core analysis, we considered the following settings. We used the Ingenuity Knowledge Base as the reference set. Because our focus was on the genetic studies of cancer pain, we included only genes and not the endogenous chemicals. We used all data sources, including Ingenuity Expert Information and Ingenuity Supported Third Party Information. We limited our analysis to human only studies and included tissues and primary cells. Both direct and indirect relationships were considered for the network analysis. When generating networks, we used the settings of a maximum of 140 genes per network and 25 networks per analysis, because the networks up to 140 genes allow for the possibility that the same network can include all focus genes [24]. Adhering to the hypothesis that highly connected molecules (called hubs) are typically associated with diseases or biological functions in humans $[21-24,29]$, we reported the most interconnected genes in the networks as the key genes of interest.

\section{Pain and head and neck cancer genetic association}

The study population included adult patients with newly diagnosed, histologically confirmed, previously untreated HNSCC. All patients were self-reported Caucasians. The study was approved by the Institutional Review Board at MD Anderson Cancer Center (MDACC), and all participants provided written informed consent.

Pre-treatment cancer pain was rated using a standardized 11-point numeric scale $(0=$ "no pain" and $10=$ "pain as bad as you can imagine") [31] at presentation of the patients before initiating cancer therapy. We considered a binary pain phenotype, where cases (severe pain) were individuals with severe pre-treatment pain (score $\geq 7$ ) and controls (non-severe pain) were individuals with non-severe pre-treatment pain (score $<7$ ). The study included 1368 HNSCC patients, with 206 severe pain cases (145 male, 61 female; mean age 57 years, standard deviation $[\mathrm{sd}]=12)$ and 1162 non-severe pain controls (915 males, 247 females; mean age 58 years, sd $=11$ ). Genotyping was conducted at MDACC, using the Illumina HumanOmniExpress-12v1 BeadChip. Samples with SNP call rates $<90 \%$ were excluded from the analysis. We included all the SNPs from this chip that were within the newly derived candidate genes in our genetic analyses. 
Statistical analyses were conducted using PLINK (v1.07) [32] and R (v2.15) software. A nearest neighbor cluster analysis based on genetic similarity was conducted to identify the clusters of individuals, which was used as a covariate in the association analysis. Deviation from Hardy-Weinberg Proportion (HWP) for each SNP was assessed by a 1 degree-of-freedom $\chi^{2}$ test or Fisher's exact test, where an expected cell count was $<5$. SNPs departing from HWP $\left(p\right.$ value $\leq 10^{-6}$ ) and minor allele frequencies $(\mathrm{MAF}) \leq 5 \%$ in all samples were excluded from the analysis. The association between each SNP genotype and pre-treatment severe pain status was assessed using multivariable unconditional logistic regression, adjusting for sex and age. We report SNPs with the lowest $p$ value belonging to a molecule (a gene or a group of genes) [33-37].

\section{Results}

\section{Literature review}

The overall study flowchart is shown in Fig. 1. Searching the PubMed database using different search terms, we identified 1579 articles. After screening the title, abstract and full text, we excluded 1557 articles for the following reasons (Table 1): (1) not human studies; (2) not published in English; (3) meta-analysis study, review or letter to the editor; (4) clinical trial studies; (5) not genetic association studies; (6) not pain-related phenotypes studies; (7) not cancer patient studies; and (8) duplicate articles from different searches. We then manually searched the reference lists of the 22 articles identified through our search and exclusion criteria and other related review articles about genetic pain studies, and further identified 14 articles. As a result, we had a total of 36 articles from which we identified the genes that will serve as our "focus genes" in order to perform the IPA core analysis (Additional file 1).

The information we retrieved from each of the studies included year of publication, first author, patient ethnicity, cancer type, sample size, phenotypes, and significant

Step1: Performed literature review; identified the focus genes used in IPA. (Table 2)

Step2: Performed the IPA core analysis based on the focus genes; obtained one significant network. (Figure 2)

Step3: In the network, identified the molecules with at least 15 connections (i.e., hubs) which were considered as candidate genes in the genetic study of pre-treatment pain in head and neck cancer patients. (Table 3)

Step4: Identified the SNPs for the candidate genes; performed the association tests; reported $p$ values for the candidate genes. (Table 6)

Fig. 1 Study flowchart genes, which are listed in Additional file 1. These studies included different cancer sites and multiple ethnicities. Different pain-related phenotypes were covered in these studies, such as absolute pain increase between baseline and follow-up, pain intensity before and after opioid administration, contact heat pain and cold pain, persistent postsurgical pain, percentage of pain relief, and aromatase inhibitor-associated musculoskeletal adverse events. We included several studies that employed phenotypes that combined pain measures with other cancer patient symptoms, such as fatigue, depressed mood and morphine side-effect scores, using symptom cluster, a tree-based approach and principal component analysis.

All the 36 articles were association studies between SNPs (or haplotypes) and cancer pain related phenotypes, using either a candidate gene study or a genomewide association study. From these articles, we identified 36 focus genes eligible for IPA core analysis for pain, which either harbor or are close to the genetic variants (SNPs or haplotypes) found to be statistically significantly associated with the pain-related phenotypes in cancer patients, as listed in Table 2. Some of the genes were implicated in multiple studies. For example, genetic variants within OPRM1 have been associated with the symptom of cancer pain in four articles [3-6]; and genetic variants within COMT have been associated with cancer pain in three articles [7, 8, 38].

\section{IPA core analysis}

Six networks were revealed from the IPA core analysis. Based on a nominal significance level of $1 \times 10^{-5}$, only one network was significant ( $p$ value of $1 \times 10^{-43}$ ), with 26 of the 36 focus genes (Fig. 2; green: focus genes with less than 15 connections; red: molecules with at least 15 connections; yellow: focus genes with at least 15 connections). In the network, the solid and dashed edges or arrows stand for direct and indirect interactions, respectively. Figure 2 shows the network of focus genes (i.e., known cancer pain-associated genes) and additional non-focus molecules directly or indirectly related to the focus genes.

We are particularly interested in the molecules with most interconnections since it is hypothesized that highly connected molecules are most likely associated with diseases or biological functions [21-24, 29]. Therefore, in Table 3, we reported the top 25 out of 140 molecules that had at least 15 connections (i.e., hubs) in the network shown in Fig. 2 (red and yellow nodes), ranked by the numbers of connections for each of the molecules. The 11 molecules in bold are focus genes. Therefore, we identified 14 additional molecules (most interconnected) that have either direct or indirect interactions with the focus genes obtained from the literature review. These were the candidate molecules of interest in the following genetic association analysis. 
Table 2 Cancer pain related genes from the literature

\begin{tabular}{|c|c|}
\hline Significant genes & References \\
\hline OPRM1 & $\begin{array}{l}\text { Klepstad P [3]; Campa D [4]; Droney JM [5]; } \\
\text { Ochroch EA [6] }\end{array}$ \\
\hline COMT & $\begin{array}{l}\text { Hickey OT [7]; Fernández-de-las-Peñas C [8]; } \\
\text { Kambur O [38] }\end{array}$ \\
\hline IL8 & $\begin{array}{l}\text { Reyes-Gibby CC [9]; Reyes-Gibby CC [12]; } \\
\text { Reyes-Gibby CC [16] }\end{array}$ \\
\hline PTGS2 & $\begin{array}{l}\text { Reyes-Gibby CC [18]; Rausch SM [81]; } \\
\text { Reyes-Gibby CC [19] }\end{array}$ \\
\hline TNFa & Reyes-Gibby CC [10]; Reyes-Gibby CC [18]; \\
\hline IL10 & Rausch SM [13]; Stephens K [17] \\
\hline CYP19A1 & Mao JJ [82]; Garcia-Giralt N [83] \\
\hline IL4 & Illi J [14]; Stephens K [17] \\
\hline IL1R1 & McCann B [15]; Stephens K [17] \\
\hline IL13 & McCann B [15]; Stephens K [17] \\
\hline ABCB1/MDR1 & Campa D [4] \\
\hline IL6 & Reyes-Gibby CC [10] \\
\hline NFKBIA & Reyes-Gibby CC [18] \\
\hline TCL1A & Ingle JN [84] \\
\hline $\mathrm{GCH} 1$ & Lötsch J [85] \\
\hline CACNG2 & Nissenbaum J [86] \\
\hline IL1RN & Rausch SM [13] \\
\hline SPON1 & Galvan A [40] \\
\hline RHBDF2 & Galvan A [40] \\
\hline ZNF235 & Galvan A [40] \\
\hline OPRK1 & Droney JM [5] \\
\hline $\operatorname{cox} 1$ & Ochroch EA [6] \\
\hline LTA & Rausch SM [81] \\
\hline ABCC2 & Sloan JA [87] \\
\hline ABCC4 & Sloan JA [87] \\
\hline CYP17A1 & Garcia-Giralt N [83] \\
\hline VDR & Garcia-Giralt N [83] \\
\hline CYP27B1 & Garcia-Giralt N [83] \\
\hline ENOS & Reyes-Gibby CC [19] \\
\hline IL1B & Reyes-Gibby CC [19] \\
\hline TNFR2 & Reyes-Gibby CC [19] \\
\hline IL10RB & Reyes-Gibby CC [19] \\
\hline IFNG1 & Stephens K [17] \\
\hline IL1R2 & Stephens K [17] \\
\hline NFKB1 & Stephens K [17] \\
\hline GFRa-2 & Wang K [88] \\
\hline
\end{tabular}

In addition to the network, the IPA core analysis also provided the most significant canonical pathways (Table 4) and biological functions (Table 5) across all the focus genes. Table 4 shows the top canonical pathways $\left(p\right.$ value $\left.<1 \times 10^{-5}\right)$ discovered by the IPA core analyses.
The significant $\mathrm{p}$-value implies over-representation of focus genes in that pathway. We also calculated ratio of the number of focus genes included in the canonical pathway divided by the total number of genes that make up the canonical pathway. The canonical pathways in Table 4 are ranked by the ratios. The most significant canonical pathway was Hepatic Cholestasis $\left(p\right.$ value $=3.16 \times 10^{-24}$ ) whereas Airway Inflammation in Asthma had the highest ratio $(0.75)$. In addition, the Table 4 also showed that the identified focus genes are mostly related to cytokine signaling, a pathway that affects the human immune system and inflammation. The proteins expressed by these genes are found in both intra- and extra-cellular matrices. In other words, focus genes that have been connected to cancer pain are not restricted to certain subcellular compartments.

Table 5 lists the top 20 biological functions discovered by the IPA core analyses, which are ranked using the scores described in Methods section ( $\log _{10}(p$ value $\left.)\right)$. The top biological functions related to the focus genes are, in general, related to inflammation. The analysis provides a measure of association of focus genes with biological functions. The smaller $p$ values imply that the association is non-random. The two most significant biological functions identified through this analysis were lipid metabolism and small molecule biochemistry, and inflammatory disease with $p$ values $1.50 \times 10^{-24}$ and $3.74 \times 10^{-24}$, respectively.

\section{Genetic association between IPA-derived genes and pre-treatment pain in HNSCC patients}

We used the 25 most interconnected molecules (i.e., hubs) identified through the IPA core analysis (Fig. 2) as the candidates in the association analysis, as listed in Table 3. Eleven of the 25 candidate molecules were focus genes identified through the literature review. In our study, the candidate molecules identified through IPA core analysis have sub-members (i.e., a group of genes). For example, $L h$, the luteinizing hormone, has two members, $C G A$ and $L H B$, and CD3 has four members: CD247, $C D 3 D, C D 3 E$ and $C D 3 G$. Also, some genes may belong to more than one molecule. For example, CGA belongs to Lh, FSH and $\mathrm{Cg}$. As a result, the 25 most interconnected molecules included a total of 82 genes which were used as the candidate genes in the association analysis. After applying quality control checks, 800 SNPs belonging to the 82 IPA-derived candidate genes were included for the total 1368 HNSCC patients (information for the 82 genes and 800 SNPs is listed in Additional file 2).

The results from the candidate gene association analysis for severe pre-treatment pain in HNSCC patients are shown in Table 6 . The first column shows the molecules identified through the IPA analyses, cell location, family, number of SNPs belonging to that molecule in 


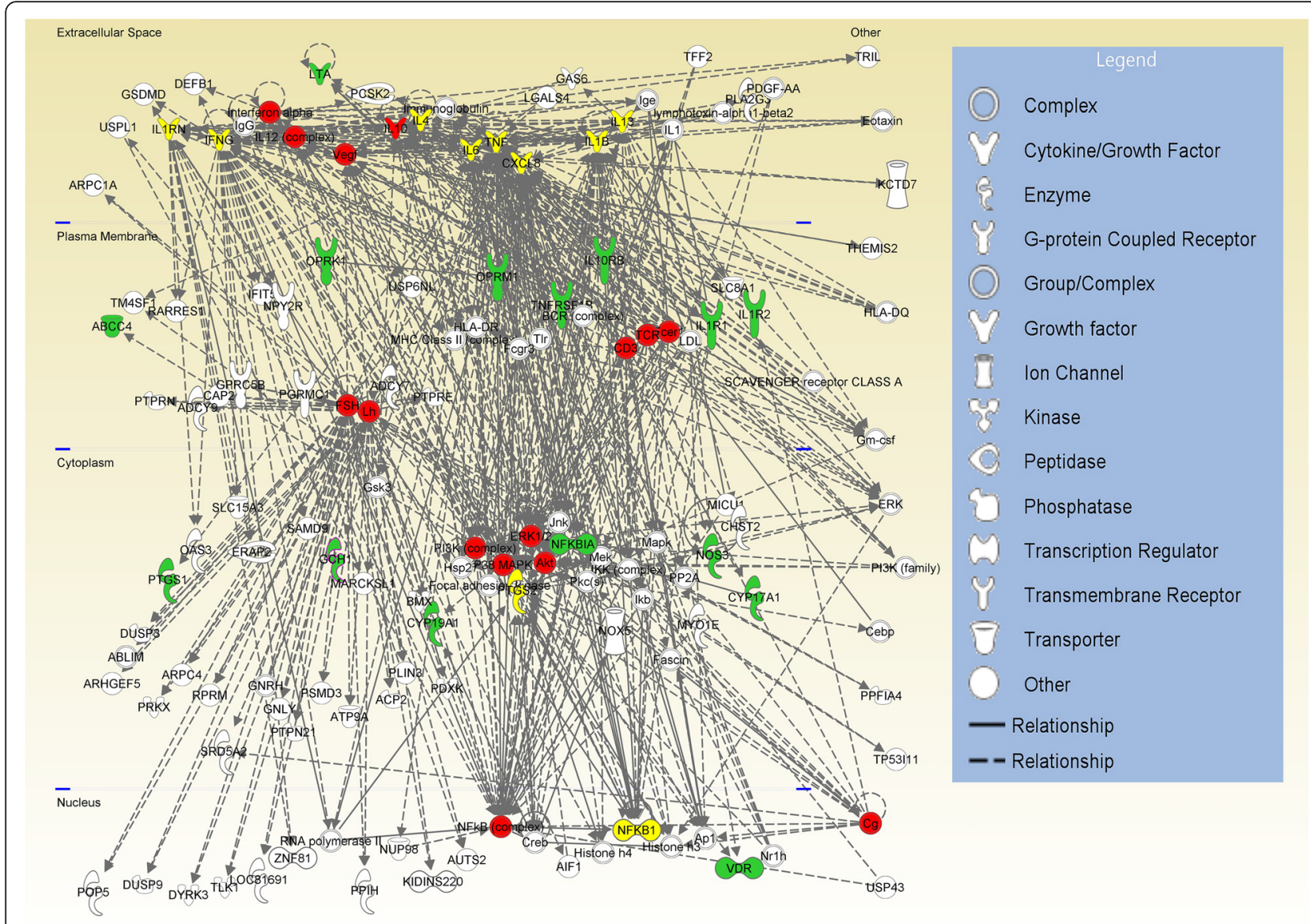

Fig. 2 The most significant network ( $p$ value $=10^{-43}$ ) generated by IPA core analysis for cancer pain using 36 focus genes based on cellular locations of the gene products. Green nodes: focus genes with less than 15 connections; red nodes: molecules with at least 15 connections; yellow: focus genes with at least 15 connections. Dashed and solid lines represent indirect and direct interactions, respectively

our study, gene name, chromosome location, and the SNP with lowest $p$ value belonging to that gene, odds ratio (OR) and $p$ value. The gene mitogen-activated protein kinase-1 (MAPK1), which belongs to the MAP kinase family and is also known as extracellular signalregulated protein kinase-2 (ERK2), showed the highest significance $\left(\mathrm{rs} 8136867, p\right.$ value $=8.92 \times 10^{-4} ; \mathrm{OR}=1.33$, $95 \%$ confidence interval [CI]: 1.13-1.58). Other genes with $p$ values less than 0.01 were PIK3C2G (a member of PI3K [complex], rs10770367, $p$ value $=1.10 \times 10^{-3}$; $\mathrm{OR}=1.46,95 \%$ CI: 1.16-1.82), TCRA (a member of TCR, rs6572493, $p$ value $=2.84 \times 10^{-3} ; \quad \mathrm{OR}=0.70,95 \% \mathrm{CI}$ : 0.55-0.88), PDGFC (platelet-derived growth factor C, rs6845322, $p$ value $=4.88 \times 10^{-3} ; \quad \mathrm{OR}=1.32,95 \% \mathrm{CI}$ : 1.09-1.60), and CD247 (a member of CD3, rs2995082, $p$ value $=7.79 \times 10^{-3} ; \mathrm{OR}=0.76,95 \%$ CI: $\left.0.62-0.93\right)$. These top five genes with germline polymorphisms showing association with pre-treatment pain in the HNSCC patients (Table 6) are listed as non-focus molecules in Table 3. Focus genes in IPA are the genes identified from the literature review as being associated with cancer pain phenotypes. Therefore, the SNPs that we have identified in this study as potentially influencing cancer pain have not been reported elsewhere.

\section{Discussion}

Genetic association studies of cancer-related pain have focused on opioid receptors [3-5, 39, 40], COMT enzyme $[7,38,39,41,42]$ and cytokines $[10,12,16-19,43]$. The primary aim of our study was to identify novel candidate genes for cancer pain through a comprehensive literature search and IPA analysis and then to assess the association between the common genetic variants within these IPAderived genes and cancer pain in HNSCC patients.

Using genotype data from 1368 HNSCC patients, we found that a germline SNP in MAPK1 ( $\mathrm{rs} 8136867, p$ value $\left.=8.92 \times 10^{-4} ; \quad \mathrm{OR}=1.33,95 \% \mathrm{CI}: 1.13-1.58\right)$ showed the highest association with cancer pain. $M A P K 1$ is involved in a number of biochemical signals 
Table 3 Molecules with at least 15 connections (i.e., hubs) in the network depicted in Fig. 2 (i.e., red and yellow nodes), ranked by the number of connections for each molecule. The molecules in boldface are focus genes

\begin{tabular}{|c|c|}
\hline $\begin{array}{l}\text { Cancer pain }{ }^{a} \\
\text { IPA symbol }\end{array}$ & \# of connections \\
\hline TNF & 64 \\
\hline IFNG & 49 \\
\hline IL1B & 44 \\
\hline CXCL8 & 42 \\
\hline IL6 & 39 \\
\hline Lh & 39 \\
\hline FSH & 38 \\
\hline NFkB (complex) & 38 \\
\hline IL10 & 31 \\
\hline P38 MAPK & 28 \\
\hline ERK1/2 & 24 \\
\hline PTGS2 & 24 \\
\hline IL4 & 23 \\
\hline IL1RN & 22 \\
\hline CD3 & 21 \\
\hline Vegf & 20 \\
\hline IL13 & 19 \\
\hline PI3K (complex) & 19 \\
\hline IL12 (complex) & 17 \\
\hline NFKB1 & 17 \\
\hline TCR & 17 \\
\hline Akt & 16 \\
\hline Fcer1 & 16 \\
\hline $\mathrm{Cg}$ & 15 \\
\hline Interferon alpha & 15 \\
\hline
\end{tabular}

${ }^{\mathrm{a}}$ In the network depicted in Fig. 2, 25 out of 140 molecules have at least 15 connections

and cellular processes such as proliferation, differentiation, transcription regulation and development [44]. It was identified as a moonlighting protein [45] because of its ability to act as a transcriptional repressor - an independent and mechanistically distinct function from its kinase activity [46]. It is activated by phosphorylation by an upstream kinase, after which it is translocated to the nucleus to phosphorylate and activate its nuclear substrate [44]. Dysregulation of MAP kinases has been associated with cancer development [47-49]. $M A P K$ pathways have also been linked to inflammation [50, 51] and pain [52-56]. The specific MAPK1 mutation, rs8136867, was reported to be associated with remission in patients with bipolar disorder and major depressive order, possibly having a potential role in neuroplasticity and inflammatory processes [57], and increased risk of developing MSI+ (micro satellite instability) tumor [48]. This increased tumor risk may be directly related to pre-treatment cancer pain since a large tumor can cause pain, especially if it exerts pressure on nearby nerve fibers. None of the genetic association studies for pain in cancer patients (Table 2) used a cohort of patients with HNSCC. Thus, our findings will be the first report on genetic variations that may be relevant to cancer pain in HHSCC patients.

In animal models, various types of nerve injuries in the dorsal root ganglia (DRG) and dorsal horn of the spinal cord have been shown to result in neuropathic pain along with phosphorylation of MAPK family such as ERK [58-61], $p 38$ [61-63] and JNK [59, 60]. Unlike $p 38$ and $J N K$, phosphorylation of ERK due to nerve injury occurs early and lasts long [64]. $M E K$ is an upstream kinase in the ERK/MAPK pathway. In animal models of neuropathic pain, $M E K$ inhibitors have been shown to be effective in alleviating pain at numerous time points [64], suggesting that the regulation of ERK/ $M A P K$ signaling may be a promising therapeutic target for the treatment of neuropathic pain. Further, Ma and Quirion [64] reviewed the literature, and suggested that efforts in suppressing multiple pain-related genes involved in neuropathic pain might target the ERK/MAPK pathway. While our study did not focus on neuropathic pain, among cancer patients, neuropathic pain is a debilitating sequela of malignancy and its treatment. To our knowledge, this study is the first to show the importance of these genes in studies of pain severity among cancer patients.

Other genes that showed potential association with cancer pain in HNSCC patients included PIK3C2G $\left(\right.$ rs10770367, $p$ value $\left.=1.10 \times 10^{-3}\right)$, TCRA $($ rs6572493, $p$ value $\left.=2.84 \times 10^{-3}\right), P D G F C($ rs6845322, $p$ value $=4.88 \times$ $\left.10^{-3}\right)$, and $C D 247\left(\right.$ rs2995082, $p$ value $\left.=7.79 \times 10^{-3}\right)$.

Although PIK3C2G has been implicated in cancer development [47, 65-67], the specific genetic variation PIK3C2G rs10770367, to our knowledge, had not been associated with any health risk prior to this study. Genes TCRA and CD247, both of which have at least 15 connections in the cancer pain network (Table 3), encode proteins that are essential to the assembly of the T-cell receptor-CD3 complex at the plasma membrane. The protein encoded by $C D 247$ is the T-cell receptor zeta; while TCRA gene encodes T cell receptor alpha locus receptor [68]. The T-cell receptor recognizes a specific antigen on the surface of other cells; while CD3 proteins are involved in signal transduction [69]. Our study showed that CD247 rs2995082 and TCRA rs6572493 SNPs are both important to pre-treatment pain in HNSCC patients. TCRA rs6572493 has not yet been associated with any health risks, but CD247 rs2995082 has been 
Table 4 Top canonical pathways discovered by the IPA core analyses of the focus genes reported to be associated with cancer pain in the literature. The pathways listed have over-representation of focus genes. The canonical pathways were ranked by ratios ${ }^{a}$

\begin{tabular}{|c|c|c|}
\hline Canonical pathways & $p$ values & Ratio \\
\hline Airway Inflammation in Asthma & $3.02 \mathrm{E}-08$ & $75.0 \%$ \\
\hline Differential Regulation of Cytokine Production in Macrophages and T Helper Cells by IL-17A and IL-17 F & 2.09E-10 & $27.8 \%$ \\
\hline Differential Regulation of Cytokine Production in Intestinal Epithelial Cells by IL-17A and IL-17 F & 8.13E-10 & $21.7 \%$ \\
\hline TNFR2 Signaling & $2.34 \mathrm{E}-09$ & $17.9 \%$ \\
\hline Role of Cytokines in Mediating Communication between Immune Cells & $6.31 \mathrm{E}-16$ & $17.3 \%$ \\
\hline IL-10 Signaling & 7.94E-17 & $14.7 \%$ \\
\hline Role of Hypercytokinemia/hyperchemokinemia in the Pathogenesis of Influenza & $1.82 \mathrm{E}-10$ & $14.6 \%$ \\
\hline T Helper Cell Differentiation & $6.31 \mathrm{E}-13$ & $11.9 \%$ \\
\hline Graft-versus-Host Disease Signaling & $2.51 \mathrm{E}-08$ & $11.4 \%$ \\
\hline Altered T Cell and B Cell Signaling in Rheumatoid Arthritis & $3.98 \mathrm{E}-14$ & $11.1 \%$ \\
\hline IL-6 Signaling & $3.16 \mathrm{E}-18$ & $10.3 \%$ \\
\hline Hepatic Cholestasis & $3.16 \mathrm{E}-24$ & $10.1 \%$ \\
\hline PPAR Signaling & $1.26 \mathrm{E}-13$ & $10.0 \%$ \\
\hline Activation of IRF by Cytosolic Pattern Recognition Receptors & $1.95 \mathrm{E}-09$ & $10.0 \%$ \\
\hline Role of PKR in Interferon Induction and Antiviral Response & $1.20 \mathrm{E}-06$ & $10.0 \%$ \\
\hline Communication between Innate and Adaptive Immune Cells & $3.98 \mathrm{E}-12$ & $9.8 \%$ \\
\hline Role of IL-17 F in Allergic Inflammatory Airway Diseases & $1.32 \mathrm{E}-06$ & $9.8 \%$ \\
\hline HMGB1 Signaling & $3.16 \mathrm{E}-16$ & $9.3 \%$ \\
\hline Hematopoiesis from Pluripotent Stem Cells & $1.78 \mathrm{E}-06$ & $9.1 \%$ \\
\hline TREM1 Signaling & 4.68E-09 & $8.7 \%$ \\
\hline Role of Pattern Recognition Receptors in Recognition of Bacteria and Viruses & $2.51 \mathrm{E}-14$ & $8.4 \%$ \\
\hline Allograft Rejection Signaling & $2.51 \mathrm{E}-06$ & $8.3 \%$ \\
\hline Crosstalk between Dendritic Cells and Natural Killer Cells & 4.37E-10 & $7.9 \%$ \\
\hline CD40 Signaling & $1.74 \mathrm{E}-07$ & $7.8 \%$ \\
\hline Type I Diabetes Mellitus Signaling & $3.16 \mathrm{E}-11$ & $7.6 \%$ \\
\hline IL-15 Signaling & $2.00 \mathrm{E}-07$ & $7.6 \%$ \\
\hline LXR/RXR Activation & $1.58 \mathrm{E}-12$ & $7.4 \%$ \\
\hline Role of IL-17A in Arthritis & 4.07E-06 & $7.4 \%$ \\
\hline Toll-like Receptor Signaling & 3.09E-07 & $6.9 \%$ \\
\hline Induction of Apoptosis by HIV1 & $5.75 \mathrm{E}-06$ & $6.8 \%$ \\
\hline PXR/RXR Activation & 7.59E-06 & $6.4 \%$ \\
\hline Hepatic Fibrosis/Hepatic Stellate Cell Activation & $2.00 \mathrm{E}-15$ & $6.1 \%$ \\
\hline Atherosclerosis Signaling & 3.63E-09 & $5.8 \%$ \\
\hline Role of Osteoblasts, Osteoclasts and Chondrocytes in Rheumatoid Arthritis & $6.31 \mathrm{E}-15$ & $5.6 \%$ \\
\hline Dendritic Cell Maturation & $3.98 \mathrm{E}-11$ & $5.3 \%$ \\
\hline NF-KB Signaling & $3.98 \mathrm{E}-11$ & $5.3 \%$ \\
\hline p38 MAPK Signaling & $1.12 \mathrm{E}-07$ & $5.1 \%$ \\
\hline Glucocorticoid Receptor Signaling & $1.26 \mathrm{E}-15$ & $5.0 \%$ \\
\hline Acute Phase Response Signaling & $1.20 \mathrm{E}-09$ & $4.8 \%$ \\
\hline LPS/IL-1 Mediated Inhibition of RXR Function & $2.29 \mathrm{E}-10$ & $4.3 \%$ \\
\hline Role of Macrophages, Fibroblasts and Endothelial Cells in Rheumatoid Arthritis & $2.00 \mathrm{E}-13$ & $4.2 \%$ \\
\hline Granulocyte Adhesion and Diapedesis & $3.31 \mathrm{E}-08$ & $4.2 \%$ \\
\hline
\end{tabular}


Table 4 Top canonical pathways discovered by the IPA core analyses of the focus genes reported to be associated with cancer pain in the literature. The pathways listed have over-representation of focus genes. The canonical pathways were ranked by ratios ${ }^{a}$ (Continued)

\begin{tabular}{lc}
\hline FXR/RXR Activation & $4.90 \mathrm{E}-06$ \\
IL-12 Signaling and Production in Macrophages & $6.17 \mathrm{E}-06$ \\
PPARa/RXRa Activation & $8.71 \mathrm{E}-07$ \\
Production of Nitric Oxide and Reactive Oxygen Species in Macrophages & $1.38 \mathrm{E}-06$ \\
\hline
\end{tabular}

${ }^{a}$ Ratio is calculated as the number of focus genes included in a canonical pathway divided by total number of genes that make up the canonical pathway

associated with celiac disease [70] and rheumatoid arthritis [71, 72].

$P D G C F-C$ is a gene that encodes platelet-derived growth factor $C$ protein. Members of the PDGF family are mitogens for cells of mesenchymal origin [73] and are regulators of cell migration, transformation, survival and apoptosis [65]. To our knowledge, PDGFC rs6845322 has not been associated with any health risk to date.

MAPK1 rs8136867, PIK3C2G rs10770367, TCRA rs6572493, $P D G F C$ rs6845322, and CD247 rs2995082 are all located in introns [74], the non-coded sequence, of their respective genes. Introns, which are usually present in most eukaryotic genes, are removed by splicing such that the mutations in this sequence were usually thought not to alter the expressed proteins. However, recent evidence has suggested that genomic variants in the noncoding sequences (introns) can lead to deleterious gene transcript variants [75] or to alterations in gene expression levels [76] that can lead to disease or increased risk of disease. For instance, intron variants of the $p 53$ gene were associated with ovarian cancer risk [77], intronic SNP rs8048002 in the $M H C$ class II transactivation gene (MHC2TA) was associated with increased risk of inflammatory disease [78], and intronic SNP rs9282860 in serine-threonine kinase 11 is a genetic risk factor in women with multiple sclerosis [79].

Among the limitations of this study is that the sizes of the networks reflect the amount of literature available on

Table 5 Top 20 diseases and functions discovered by IPA core analyses of focus genes reported to be associated with cancer pain in the literature ${ }^{a}$

\begin{tabular}{|c|c|c|}
\hline Categories & Function annotation & $p$ Value \\
\hline Lipid metabolism, small molecule biochemistry & Synthesis of prostaglandin & $1.50 \mathrm{E}-24$ \\
\hline Inflammatory disease & Chronic inflammatory disorder & $3.74 \mathrm{E}-24$ \\
\hline Drug metabolism, lipid metabolism, small molecule biochemistry & Synthesis of prostaglandin E2 & 4.34E-24 \\
\hline Lipid metabolism, molecular transport, small molecule biochemistry & Concentration of eicosanoid & 2.19E-21 \\
\hline Gastrointestinal disease, inflammatory disease & Inflammatory bowel disease & 1.03E-20 \\
\hline Lipid metabolism, molecular transport, small molecule biochemistry & Concentration of lipid & 4.13E-20 \\
\hline Lipid metabolism, small molecule biochemistry & Fatty acid metabolism & $6.51 \mathrm{E}-20$ \\
\hline Lipid metabolism, small molecule biochemistry & Synthesis of lipid & $1.01 \mathrm{E}-19$ \\
\hline Gastrointestinal disease, inflammatory disease, inflammatory response & Ulcerative colitis & $1.74 \mathrm{E}-19$ \\
\hline $\begin{array}{l}\text { Connective tissue disorders, immunological disease, inflammatory } \\
\text { disease, skeletal and muscular disorders }\end{array}$ & Rheumatoid arthritis & 1.84E-19 \\
\hline Connective tissue, inflammatory disease, skeletal and muscular disorders & Rheumatic disease & 4.11E-19 \\
\hline Connective tissue disorders, inflammatory disease, skeletal and muscular disorders & Arthritis & 7.15E-19 \\
\hline Inflammatory response & Inflammation of organ & 1.19E-18 \\
\hline Immunological disease & Systemic autoimmune syndrome & 1.57E-18 \\
\hline Infectious disease & Sepsis & $3.20 \mathrm{E}-18$ \\
\hline Inflammatory response & Inflammation of body region & 4.40E-17 \\
\hline Lipid metabolism, molecular transport, small molecule biochemistry & Concentration of prostaglandin & $4.51 \mathrm{E}-16$ \\
\hline Infectious disease & Dengue hemorrhagic fever & $6.48 \mathrm{E}-16$ \\
\hline Inflammatory disease, organismal injury and abnormalities, respiratory disease & Acute respiratory distress syndrome & $1.53 \mathrm{E}-15$ \\
\hline $\begin{array}{l}\text { Cell-to-cell signaling and interaction, hematological system development } \\
\text { and function, immune cell trafficking, inflammatory response }\end{array}$ & Activation of dendritic cells & $2.59 \mathrm{E}-15$ \\
\hline
\end{tabular}

${ }^{\text {aRanked by } p \text { values }}$ 
Table 6 Results of genetic associated analysis for pre-treatment pain in 1368 head and neck cancer patients (206 severe pain cases and 1162 non-severe pain controls), using the hubs (most interconnected molecules) obtained from IPA core analysis as the candidate molecules. The IPA symbol represents either a gene or a group of genes. The $p$ value represents the most significant $p$ value within a gene or a gene group. The molecules in boldface are focus genes

\begin{tabular}{|c|c|c|c|c|c|c|c|c|}
\hline IPA symbol & Location & Family & \# of SNPS & Genes & Chr & rs\# & OR & $P$ value \\
\hline TNF & Extracellular space & Cytokine & 3 & TNF & 6 & rs1800630 & 1.20 & $1.78 \mathrm{E}-01$ \\
\hline IFNG & Extracellular space & Cytokine & 2 & IFNG & 12 & rs2069727 & 0.84 & $8.85 \mathrm{E}-02$ \\
\hline IL1B & Extracellular space & Cytokine & 4 & IL1B & 2 & rs16944 & 0.77 & $3.79 \mathrm{E}-02$ \\
\hline CXCL8 & Extracellular space & Cytokine & 1 & CXCL8 & 4 & rs2227543 & 1.09 & $3.78 \mathrm{E}-01$ \\
\hline IL6 & Extracellular space & Cytokine & 7 & IL6 & 7 & rs2069835 & 1.45 & $8.21 \mathrm{E}-02$ \\
\hline Lh & Plasma membrane & Complex & 5 & CGA & 6 & rs9359730 & 1.26 & $3.48 \mathrm{E}-02$ \\
\hline FSH & Plasma membrane & Complex & 4 & CGA & 6 & rs9359730 & 1.26 & $3.48 \mathrm{E}-02$ \\
\hline NFkB (complex) & Nucleus & Complex & 22 & NFKB2 & 10 & rs7897947 & 1.29 & $6.78 \mathrm{E}-02$ \\
\hline IL10 & Extracellular space & Cytokine & 4 & IL10 & 1 & rs3021094 & 1.11 & $6.08 \mathrm{E}-01$ \\
\hline P38 MAPK & Cytoplasm & Group & 33 & MAPK1 & 22 & rs8136867 & 1.33 & $8.92 \mathrm{E}-04$ \\
\hline ERK1/2 & Cytoplasm & Group & 13 & MAPK1 & 22 & rs8136867 & 1.33 & $8.92 \mathrm{E}-04$ \\
\hline PTGS2 & Cytoplasm & Enzyme & 3 & PTGS2 & 1 & rs5275 & 1.23 & $5.35 \mathrm{E}-02$ \\
\hline IL4 & Extracellular space & Cytokine & 5 & IL4 & 5 & rs2243248 & 0.81 & $3.19 \mathrm{E}-01$ \\
\hline IL1RN & Extracellular space & Cytokine & 12 & IL1RN & 2 & rs17042917 & 0.77 & $1.43 \mathrm{E}-01$ \\
\hline CD3 & Plasma membrane & Complex & 44 & CD247 & 1 & rs2995082 & 0.76 & $7.79 \mathrm{E}-03$ \\
\hline Vegf & Extracellular space & Group & 47 & PDGFC & 4 & rs6845322 & 1.32 & $4.88 \mathrm{E}-03$ \\
\hline IL13 & Extracellular space & Cytokine & 5 & IL13 & 5 & rs1881457 & 0.84 & $2.44 \mathrm{E}-01$ \\
\hline PI3K (complex) & Cytoplasm & Complex & 196 & PIK3C2G & 12 & rs10770367 & 1.46 & $1.10 \mathrm{E}-03$ \\
\hline IL12 (complex) & Extracellular space & Complex & 10 & IL12B & 5 & rs730691 & 0.77 & $1.68 \mathrm{E}-02$ \\
\hline NFKB1 & Nucleus & Transcription regulator & 9 & NFKB1 & 4 & rs1609798 & 1.20 & $9.42 \mathrm{E}-02$ \\
\hline TCR & Plasma membrane & Complex & 378 & TCRA & 14 & rs6572493 & 0.70 & $2.84 \mathrm{E}-03$ \\
\hline Akt & Cytoplasm & Group & 33 & AKT2 & 19 & rs892120 & 1.35 & $3.15 \mathrm{E}-02$ \\
\hline Fcer1 & Plasma membrane & Complex & 15 & FCER1G & 1 & rs11587213 & 0.68 & $1.68 \mathrm{E}-02$ \\
\hline $\mathrm{Cg}$ & Other & Complex & 8 & CGA & 6 & rs9359730 & 1.26 & $3.48 \mathrm{E}-02$ \\
\hline Interferon alpha & Extracellular space & Group & 14 & IFNA7 & 9 & rs4977686 & 1.20 & $7.51 \mathrm{E}-02$ \\
\hline
\end{tabular}

the focus genes. Also, edges are simplified in that IPA designates only a single edge between each pair of molecules in a network regardless of the number of interactions the two molecules share. Furthermore, the identified association between MAPK1/ERK2 should be viewed as preliminary and exploratory. Multiple comparison adjustment was not performed in this analysis, and none of the associations reported would be statistically significant if such adjustments were performed. However, as the analysis in this study was considered as preliminary and exploratory, the multiple comparison adjustments are usually not required [80]. Despite these limitations however, the present study identified novel, potentially biologically meaningful candidate genes associated with cancer pain in HNSCC patients. These genes, though requiring further validation in future studies using independent data as well as other cancer sites, may allow researchers to not only identify a subgroup of the patient population and higher susceptibility for cancer associated pain and symptoms, but may also provide insight into the etiology of cancer associated pain. This in turn can be used to inform clinical decision making and help develop targeted treatment strategies for this subgroup.

\section{Conclusions}

In conclusion, IPA is able to use large-scale information to produce comprehensive networks of genes and underlying biological pathways implicated in a phenotype. Future studies should aim to target these molecules and pathways while also minimizing adverse effects due to a lack of specificity.

\section{Availability of data and materials}

The data bases used for the network generation of this article are available in the Ingenuity Knowledge Base by Ingenuity Pathway Analysis (IPA; Ingenuity Systems, www.ingenuity.com). The list of articles and genes 
identified through the literature search are provided in Additional file 1 . The data used for the association analysis of this article is from a study of squamous cell carcinoma of the head and neck conducted at The University of Texas MD Anderson Cancer Center. The list of all 800 SNPs used from this study is provided in Additional file 2. The data supporting the results of this article are included within the article and its additional files: Additional files 1 and 2 which are referenced in the main text.

\section{Additional files}

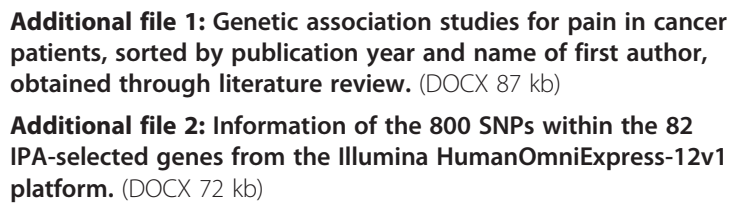

\section{Competing interests}

The authors declare that they have no competing interests.

\begin{abstract}
Authors' contributions
All co-authors are justifiably credited with authorship, according to the authorship criteria. Final approval is given by each co-author. CCR conceptualized the study and drafted the manuscript. JW performed the literature review, conducted pathway analysis and drafted the manuscript. MRS investigated the biological functions of the IPA derived genes and drafted the manuscript. RY performed genetic association analysis for pain in HNSCC patients. SJY provided critical advice for the content of the manuscript and revised the draft. SS conceptualized the study, helped to draft the manuscript and provided critical revisions for important intellectual content. All authors read and approved the final manuscript.
\end{abstract}

\section{Acknowledgements}

This work was supported by National Institutes of Health through grants R01DE022891 (CCR and SS), 1R01CA131324 (SS), R25DA026120 (SS), and R03CA192197 (JW). This research was also supported in part by the Barnhart Family Distinguished Professorship in Targeted Therapy (SS) and the National Cancer Institute grant CA016672. We thank Dr. Stephanie Melkonian for her comments on the manuscript.

\section{Author details}

${ }^{1}$ Department of Emergency Medicine, The University of Texas MD Anderson Cancer Center, Houston, TX 77030, U.S.A.. ${ }^{2}$ Department of Biostatistics, The University of Texas MD Anderson Cancer Center, Houston, TX 77030, U.S.A. ${ }^{3}$ Department of Epidemiology, The University of Texas MD Anderson Cancer Center, Houston, TX 77030, U.S.A.

Received: 17 July 2015 Accepted: 5 February 2016 Published online: 13 February 2016

\section{References}

1. A snapshot of head and neck cancer. 2015. http://www.cancer.gov/ research/progress/snapshots/headandneck.

2. Reyes-Gibby CC, Anderson KO, Merriman KW, Todd KH, Shete SS, Hanna EY. Survival patterns in squamous cell carcinoma of the head and neck: pain as an independent prognostic factor for survival. J Pain. 2014;15:1015-22.

3. Klepstad P, Rakvag TT, Kaasa S, Holthe M, Dale O, Borchgrevink PC, et al. The $118 \mathrm{~A}>\mathrm{G}$ polymorphism in the human mu-opioid receptor gene may increase morphine requirements in patients with pain caused by malignant disease. Acta Anaesthesiol Scand. 2004;48:1232-9.

4. Campa D, Gioia A, Tomei A, Poli P, Barale R. Association of ABCB1/MDR1 and OPRM1 gene polymorphisms with morphine pain relief. Clin Pharmaco Ther. 2008;83:559-66.
5. Droney JM, Gretton SK, Sato H, Ross JR, Branford R, Welsh Kl, et al. Analgesia and central side-effects: two separate dimensions of morphine response. Br J Clin Pharmacol. 2013;75:1340-50.

6. Ochroch EA, Vachani A, Gottschalk A, Kanetsky PA. Natural variation in the mu-opioid gene OPRM1 predicts increased pain on third day after thoracotomy. Clin J Pain. 2012;28:747-54.

7. Hickey OT, Nugent NF, Burke SM, Hafeez P, Mudrakouski AL, Shorten GD. Persistent pain after mastectomy with reconstruction. J Clin Anesth. 2011;23:482-8.

8. Fernandez-de-las-Penas C, Fernandez-Lao C, Cantarero-Villanueva I, Ambite-Quesada S, Rivas-Martinez I, del Moral-Avila R, et al. Catechol-Omethyltransferase genotype (Val158met) modulates cancer-related fatigue and pain sensitivity in breast cancer survivors. Breast Cancer Res Treat. 2012;133:405-12.

9. Reyes-Gibby CC, Spitz M, Wu X, Merriman K, Etzel C, Bruera E, et al. Cytokine genes and pain severity in lung cancer: exploring the influence of TNFalpha-308 G/A IL6-174G/C and IL8-251 T/A. Cancer Epidemiol Biomarkers Prev. 2007;16:2745-51.

10. Reyes-Gibby CC, El Osta B, Spitz MR, Parsons $H$, Kurzrock R, Wu X, et al. The influence of tumor necrosis factor-alpha $-308 \mathrm{G} / \mathrm{A}$ and IL-6 -174 G/C on pain and analgesia response in lung cancer patients receiving supportive care. Cancer Epidemiol Biomarkers Prev. 2008;17:3262-7.

11. Reyes-Gibby CC, Morrow PK, Buzdar A, Shete S. Chemotherapy-induced peripheral neuropathy as a predictor of neuropathic pain in breast cancer patients previously treated with paclitaxel. J Pain. 2009;10:1146-50.

12. Reyes-Gibby CC, Shete S, Yennurajalingam S, Frazier M, Bruera E, Kurzrock R, et al. Genetic and nongenetic covariates of pain severity in patients with adenocarcinoma of the pancreas: assessing the influence of cytokine genes. J Pain Symptom Manage. 2009;38:894-902.

13. Rausch SM, Clark MM, Patten C, Liu H, Felten S, Li Y, et al. Relationship between cytokine gene single nucleotide polymorphisms and symptom burden and quality of life in lung cancer survivors. Cancer. 2010;116:4103-13.

14. Illi J, Miaskowski C, Cooper B, Levine JD, Dunn L, West C, et al. Association between pro- and anti-inflammatory cytokine genes and a symptom cluster of pain, fatigue, sleep disturbance, and depression. Cytokine. 2012;58:437-47.

15. McCann B, Miaskowski C, Koetters T, Baggott C, West C, Levine JD, et al. Associations between pro- and anti-inflammatory cytokine genes and breast pain in women prior to breast cancer surgery. J Pain. 2012;13:425-37.

16. Reyes-Gibby CC, Wang J, Spitz M, Wu X, Yennurajalingam S, Shete S. Genetic variations in interleukin- 8 and interleukin-10 are associated with pain, depressed mood, and fatigue in lung cancer patients. J Pain Symptom Manage. 2013;46:161-72.

17. Stephens K, Cooper BA, West C, Paul SM, Baggott CR, Merriman JD, et al. Associations between cytokine gene variations and severe persistent breast pain in women following breast cancer surgery. J Pain. 2014;15:169-80.

18. Reyes-Gibby CC, Spitz MR, Yennurajalingam S, Swartz M, Gu J, Wu X, et al. Role of inflammation gene polymorphisms on pain severity in lung cancer patients. Cancer Epidemiol Biomarkers Prev. 2009;18:2636-42.

19. Reyes-Gibby CC, Swartz MD, Yu X, Wu X, Yennurajalingam S, Anderson KO, et al. Symptom clusters of pain, depressed mood, and fatigue in lung cancer: assessing the role of cytokine genes. Support Care Cancer. 2013;21:3117-25.

20. Valencia-Cruz Al, Uribe-Figueroa LI, Galindo-Murillo R, Baca-Lopez K, Gutierrez $A G$, Vazquez-Aguirre $A$, et al. Whole genome gene expression analysis reveals casiopeina-induced apoptosis pathways. PLoS One. 2013;8, e54664.

21. Barabasi AL, Gulbahce N, Loscalzo J. Network medicine: a network-based approach to human disease. Nat Rev Genet. 2011;12:56-68.

22. Jeong H, Tombor B, Albert R, Oltvai ZN, Barabasi AL. The large-scale organization of metabolic networks. Nature. 2000;407:651-4.

23. Muurling T, Stankovic KM. Metabolomic and network analysis of pharmacotherapies for sensorineural hearing loss. Otol Neurotol. 2014;35:1-6.

24. Stamatiou GA, Stankovic KM. A comprehensive network and pathway analysis of human deafness genes. Otol Neurotol. 2013;34:961-70.

25. Reyes-Gibby CC, Yuan C, Wang J, Yeung SC, Shete S. Gene network analysis shows immune-signaling and ERK1/2 as novel genetic markers for multiple addiction phenotypes: alcohol, smoking and opioid addiction. BMC Syst Biol. 2015;9:25.

26. Ingenuity Pathway Analysis software. 2014. http://www.ingenuity.com/.

27. Kramer A, Green J, Pollard Jr J, Tugendreich S. Causal analysis approaches in ingenuity pathway analysis. Bioinformatics. 2014;30:523-30.

28. Ingenuity Pathways Analysis (IPA) of Large Datasets. 2014. http://www.usc.edu/ hsc/nml/assets/bioinfo/IPA/Data\%20Analysis\%20training\%20Handouts.pdf. 
29. IPA Network Generation Algorithm. 2014. http://www.ingenuity.com/wpcontent/themes/ingenuitytheme/pdf/ipa/IPA-netgen-algorithmwhitepaper.pdf.

30. Calculating and Interpreting the p-values for Functions, Pathways and Lists in IPA. 2014. http://www.ingenuity.com/wp-content/themes/ingenuityqiagen/pdf/ipa/functions-pathways-pval-whitepaper.pdf.

31. Caraceni A, Cherny N, Fainsinger R, Kaasa S, Poulain P, Radbruch L, et al. Pain measurement tools and methods in clinical research in palliative care: recommendations of an expert Working Group of the European Association of palliative care. J Pain Symptom Manage. 2002;23:239-55.

32. Purcell S, Neale B, Todd-Brown K, Thomas L, Ferreira MA, Bender D, et al. PLINK: a tool set for whole-genome association and population-based linkage analyses. Am J Hum Genet. 2007:81:559-75.

33. Wang K, Li M, Hakonarson H. Analysing biological pathways in genomewide association studies. Nat Rev Genet. 2010;11:843-54.

34. Fridley BL, Biernacka JM. Gene set analysis of SNP data: benefits, challenges, and future directions. Eur J Hum Genet. 2011;19:837-43.

35. Askland K, Read C, O'Connell C, Moore JH. Ion channels and schizophrenia: a gene set-based analytic approach to GWAS data for biological hypothesis testing. Hum Genet. 2012;131:373-91.

36. Ersland KM, Christoforou A, Stansberg C, Espeseth T, Mattheisen M, Mattingsdal M, et al. Gene-based analysis of regionally enriched cortical genes in GWAS data sets of cognitive traits and psychiatric disorders. PLoS One. 2012;7, e31687.

37. Shete S, Hosking FJ, Robertson LB, Dobbins SE, Sanson M, Malmer B, et al. Genome-wide association study identifies five susceptibility loci for glioma. Nat Genet. 2009;41:899-904.

38. Kambur O, Kaunisto MA, Tikkanen E, Leal SM, Ripatti S, Kalso EA. Effect of catechol-o-methyltransferase-gene (COMT) variants on experimental and acute postoperative pain in 1,000 women undergoing surgery for breast cancer. Anesthesiology. 2013;119:1422-33.

39. Reyes-Gibby CC, Shete S, Rakvag T, Bhat SV, Skorpen F, Bruera E, et al. Exploring joint effects of genes and the clinical efficacy of morphine for cancer pain: OPRM1 and COMT gene. Pain. 2007;130:25-30.

40. Galvan A, Skorpen F, Klepstad P, Knudsen AK, Fladvad T, Falvella FS, et al. Multiple Loci modulate opioid therapy response for cancer pain. Clin Cancer Res. 2011;17:4581-7.

41. Rakvag T, Klepstad P, Baar C, Kvam TM, Dale O, Kaasa S, et al. The Val158Met polymorphism of the human catechol-O-methyltransferase (COMT) gene may influence morphine requirements in cancer pain patients. Pain. 2005;116:73-8.

42. Rakvag TT, Ross JR, Sato H, Skorpen F, Kaasa S, Klepstad P. Genetic variation in the catechol-O-methyltransferase (COMT) gene and morphine requirements in cancer patients with pain. Mol Pain. 2008;4:64.

43. Uceyler N, Rogausch JP, Toyka KV, Sommer C. Differential expression of cytokines in painful and painless neuropathies. Neurology. 2007;69:42-9.

44. NCBI. Gene MAPK1. 2015. http://www.ncbi.nlm.nih.gov/gene/5594. Accessed Mar 2015

45. Huberts $\mathrm{DH}$, van der Klei IJ. Moonlighting proteins: an intriguing mode of multitasking. Biochim Biophys Acta. 2010;1803:520-5.

46. Hu S, Xie Z, Onishi A, Yu X, Jiang L, Lin J, et al. Profiling the human proteinDNA interactome reveals ERK2 as a transcriptional repressor of interferon signaling. Cell. 2009;139:610-22.

47. Sun W, Quan C, Huang Y, Ji W, Yu L, Li X, et al. Constitutive ERK1/2 activation contributes to production of double minute chromosomes in tumour cells. J Pathol. 2015;235:14-24

48. Slattery ML, Lundgreen A, Wolff RK. MAP kinase genes and colon and rectal cancer. Carcinogenesis. 2012;33:2398-408.

49. Wagner EF, Nebreda AR. Signal integration by JNK and p38 MAPK pathways in cancer development. Nat Rev Cancer. 2009;9:537-49.

50. Zarubin T, Han J. Activation and signaling of the p38 MAP kinase pathway. Cell Res. 2005;15:11-8.

51. Hollenbach E, Neumann M, Vieth M, Roessner A, Malfertheiner P, Naumann M. Inhibition of p38 MAP kinase- and RICK/NF-kappaB-signaling suppresses inflammatory bowel disease. FASEB J. 2004;18:1550-2.

52. Liu CY, Lu ZY, Li N, Yu LH, Zhao YF, Ma B. The role of large-conductance, calcium-activated potassium channels in a rat model of trigeminal neuropathic pain. Cephalalgia. 2015;35:16-35.

53. Kondo T, Sakurai J, Miwa H, Noguchi K. Activation of p38 MAPK through transient receptor potential $\mathrm{A} 1$ in a rat model of gastric distension-induced visceral pain. Neuroreport. 2013;24:68-72.
54. Crown ED. The role of mitogen activated protein kinase signaling in microglia and neurons in the initiation and maintenance of chronic pain. Exp Neurol. 2012;234:330-9.

55. Ji RR, Gereau RWT, Malcangio M, Strichartz GR. MAP kinase and pain. Brain Res Rev. 2009;60:135-48.

56. Mizushima T, Obata K, Yamanaka H, Dai Y, Fukuoka T, Tokunaga A, et al. Activation of p38 MAPK in primary afferent neurons by noxious stimulation and its involvement in the development of thermal hyperalgesia. Pain. 2005:113:51-60

57. Calati R, Crisafulli C, Balestri M, Serretti A, Spina E, Calabro M, et al. Evaluation of the role of MAPK1 and CREB1 polymorphisms on treatment resistance, response and remission in mood disorder patients. Prog Neuropsychopharmacol Biol Psychiatry. 2013;44:271-8.

58. Zhuang ZY, Gerner P, Woolf CJ, Ji RR. ERK is sequentially activated in neurons, microglia, and astrocytes by spinal nerve ligation and contributes to mechanical allodynia in this neuropathic pain model. Pain. 2005:114:149-59.

59. Ma W, Quirion R. Partial sciatic nerve ligation induces increase in the phosphorylation of extracellular signal-regulated kinase (ERK) and c-Jun $\mathrm{N}$-terminal kinase (JNK) in astrocytes in the lumbar spinal dorsal horn and the gracile nucleus. Pain. 2002;99:175-84.

60. Obata K, Yamanaka H, Kobayashi K, Dai Y, Mizushima T, Katsura H, et al. Role of mitogen-activated protein kinase activation in injured and intact primary afferent neurons for mechanical and heat hypersensitivity after spinal nerve ligation. J Neurosci. 2004;24:10211-22.

61. Obata K, Yamanaka H, Dai Y, Mizushima T, Fukuoka T, Tokunaga A, et al. Differential activation of MAPK in injured and uninjured DRG neurons following chronic constriction injury of the sciatic nerve in rats. Eur J Neurosci. 2004;20:2881-95.

62. Jin SX, Zhuang ZY, Woolf CJ, Ji RR. p38 mitogen-activated protein kinase is activated after a spinal nerve ligation in spinal cord microglia and dorsal root ganglion neurons and contributes to the generation of neuropathic pain. J Neurosci. 2003;23:4017-22.

63. Tsuda M, Mizokoshi A, Shigemoto-Mogami Y, Koizumi S, Inoue K. Activation of p38 mitogen-activated protein kinase in spinal hyperactive microglia contributes to pain hypersensitivity following peripheral nerve injury. Glia. 2004;45:89-95.

64. Ma W, Quirion R. The ERK/MAPK pathway, as a target for the treatment of neuropathic pain. Expert Opin Ther Targets. 2005;9:699-713.

65. Hurst Jr NJ, Najy AJ, Ustach CV, Movilla L, Kim HR. Platelet-derived growth factor-C (PDGF-C) activation by serine proteases: implications for breast cancer progression. Biochem J. 2012:441:909-18.

66. NCBI. ClinVar PIK3C2G. 2015. http://www.ncbi.nlm.nih.gov/clinvar/ ?term=PIK3C2G\%5Bgene\%5D. Accessed Mar 2015.

67. NCBI. Gene PIK3C2G. 2015. http://www.ncbi.nlm.nih.gov/gene/5288. Accessed Mar 2015

68. NCBI Gene. 2015. http://www.ncbi.n/m.nih.gov/gene/919; http://www.ncbi. nlm.nih.gov/gene/6955. Accessed Mar 2015.

69. VioCARTA Pathways. 2016. https://www.qiagen.com/us/shop/genes-andpathways/pathway-details/?pwid=426. Accessed Feb 2016.

70. Dubois PC, Trynka G, Franke L, Hunt KA, Romanos J, Curtotti A, et al. Multiple common variants for celiac disease influencing immune gene expression. Nat Genet. 2010:42:295-302.

71. Zhernakova A, Stahl EA, Trynka G, Raychaudhuri S, Festen EA, Franke L, et al. Meta-analysis of genome-wide association studies in celiac disease and rheumatoid arthritis identifies fourteen non-HLA shared loci. PLoS Genet. 2011;7, e1002004

72. Stahl EA, Raychaudhuri S, Remmers EF, Xie G, Eyre S, Thomson BP, et al. Genome-wide association study meta-analysis identifies seven new rheumatoid arthritis risk loci. Nat Genet. 2010:42:508-14.

73. NCBI. Gene PDGFC. 2015. http://www.ncbi.nlm.nih.gov/gene/56034. Accessed Mar 2015.

74. NCBI dbSNP. 2015. http://www.ncbi.nlm.nih.gov/snp/. Accessed Mar 2015.

75. Pagani F, Baralle FE. Genomic variants in exons and introns: identifying the splicing spoilers. Nat Rev Genet. 2004;5:389-96.

76. Choi JW, Park CS, Hwang M, Nam HY, Chang HS, Park SG, et al. A common intronic variant of CXCR3 is functionally associated with gene expression levels and the polymorphic immune cell responses to stimuli. J Allergy Clin Immunol. 2008;122(1119-1126), e1117.

77. Wang-Gohrke S, Weikel W, Risch H, Vesprini D, Abrahamson J, Lerman C, et al. Intron variants of the p53 gene are associated with increased risk for 
ovarian cancer but not in carriers of BRCA1 or BRCA2 germline mutations. Br J Cancer. 1999;81:179-83.

78. Vargas-Alarcon G, Posadas-Romero C, Posadas-Sanchez R, Martinez-Alvarado R, Gonzalez-Pacheco H, Martinez-Sanchez C, et al. The variant rs8048002 T > C in intron 3 of the MHC2TA gene is associated with risk of developing acute coronary syndrome. Cytokine. 2015;71:268-71.

79. Boullerne Al, Skias D, Hartman EM, Testai FD, Kalinin S, Polak PE, et al. A singlenucleotide polymorphism in serine-threonine kinase 11, the gene encoding liver kinase B1, is a risk factor for multiple sclerosis. ASN Neuro. 2015;7.

80. Schochet PZ. Technical methods report: Guidelines for multiple testing in impact evaluations (NCEE No, 2008-4018). National Center for Educational Evaluation and Regional Assistance, Institute of Education Sciences, U.S. Washington, DC: Department of Education; 2008.

81. Rausch SM, Gonzalez BD, Clark MM, Patten C, Felten S, Liu H, et al. SNPs in PTGS2 and LTA predict pain and quality of life in long term lung cancer survivors. Lung Cancer. 2012;77:217-23.

82. Mao JJ, Su HI, Feng R, Donelson ML, Aplenc R, Rebbeck TR, et al. Association of functional polymorphisms in CYP19A1 with aromatase inhibitor associated arthralgia in breast cancer survivors. Breast Cancer Res. 2011;13:R8.

83. Garcia-Giralt N, Rodriguez-Sanz M, Prieto-Alhambra D, Servitja S, Torres-Del Pliego E, Balcells $\mathrm{S}$, et al. Genetic determinants of aromatase inhibitorrelated arthralgia: the B-ABLE cohort study. Breast Cancer Res Treat. 2013;140:385-95.

84. Ingle JN, Schaid DJ, Goss PE, Liu M, Mushiroda T, Chapman JA, et al. Genome-wide associations and functional genomic studies of musculoskeletal adverse events in women receiving aromatase inhibitors. J Clin Oncol. 2010;28:4674-82.

85. Lotsch J, Klepstad P, Doehring A, Dale O. A GTP cyclohydrolase 1 genetic variant delays cancer pain. Pain. 2010;148:103-6.

86. Nissenbaum J, Devor M, Seltzer Z, Gebauer M, Michaelis M, Tal M, et al. Susceptibility to chronic pain following nerve injury is genetically affected by CACNG2. Genome Res. 2010;20:1180-90.

87. Sloan JA, de Andrade M, Decker P, Wampfler J, Oswold C, Clark M, et al. Genetic variations and patient-reported quality of life among patients with lung cancer. J Clin Oncol. 2012;30:1699-704.

88. Wang K, Demir IE, D'Haese JG, Tieftrunk E, Kujundzic K, Schorn S, et al. The neurotrophic factor neurturin contributes toward an aggressive cancer cell phenotype, neuropathic pain and neuronal plasticity in pancreatic cancer. Carcinogenesis. 2014;35:103-13.

\section{Submit your next manuscript to BioMed Central and we will help you at every step:}

- We accept pre-submission inquiries

- Our selector tool helps you to find the most relevant journal

- We provide round the clock customer support

- Convenient online submission

- Thorough peer review

- Inclusion in PubMed and all major indexing services

- Maximum visibility for your research

Submit your manuscript at www.biomedcentral.com/submit

C Biomed Central 